\title{
Metabolic syndrome and cognitive performance in the elderly
}

\author{
Marianna Rinaldi, ${ }^{1}$ Giuseppe Graffi, ${ }^{2}$ Salvatore Gallone, ${ }^{3}$ Emma Rabino Massa ${ }^{1}$ \\ ${ }^{1}$ Laboratory of Anthropology, Department of Life Sciences and System Biology, University of \\ Torino; ${ }^{2}$ Local Healthcare Service - ASL TO3, Susa (TO); ${ }^{3}$ Laboratory of Neurogenetics, \\ Department of Neuroscience, University of Torino, Italy
}

\begin{abstract}
Metabolic syndrome (MetS) is a cluster of conditions, each of which represents a risk factor for cardiovascular disease: central obesity, hyperglycemia, dyslipidemia and hypertension. In different recent studies, MetS has been associated with an accelerate cognitive decline in the elderly. The aim of our research was to investigate the relationship between MetS and cognitive performance in 174 italian elderly people living in Val Cenischia (Piedmont, Italy). Mini mental state examination (MMSE) has been administered to assess the cognitive status of all participants. The prevalence of MetS is $50.3 \%$ (51.3 and $49.5 \%$ for males and females, respectively). Our results confirm the association between MetS and worse cognitive performance in the elderly: an increased number of MetS components is associated with an increased risk of developing cognitive impairment (odds ratio=1.54; confidence interval 95\%:1.04-2.28; $\mathrm{P}<0.05$ ).
\end{abstract}

\section{Introduction}

Metabolic syndrome (MetS) is a cluster of conditions, each of which represents a risk factor for cardiovascular disease: central obesity, hyperglycemia, dyslipidemia and hypertension. MetS can be diagnosed when three or more of these criteria are present [National Cholesterol Education Program - Adult Treatment Panel III (NCEP ATP III) criteria]: waist circumference $\geq 102 \mathrm{~cm}$ (male) or $\geq 88 \mathrm{~cm}$ (female); triglycerides $>150 \mathrm{mg} / \mathrm{dL}$ or lipid lowering drug use; highdensity lipoprotein cholesterol (HDL-C) $<40 \mathrm{mg} / \mathrm{dL}$ (male) or $<50$

Correspondence: Marianna Rinaldi, Laboratory of Anthropology, Department of Life Sciences and Systematic Biology, University of Torino, via Accademia Albertina 13, 10123 Torino, Italy.

Tel/ Fax: +39.011.6704546.

E-mail: marianna.rinaldi@unito.it

Key words: metabolic syndrome, cognitive decline, aging, MMSE.

(C) Copyright M. Rinaldi et al., 2014

Licensee PAGEPress, Italy

Journal of Biological Research 2014; 87:2132

doi:10.4081/jbr.2014.2132

This article is distributed under the terms of the Creative Commons Attribution Noncommercial License (by-nc 3.0) which permits any noncommercial use, distribution, and reproduction in any medium, provided the original author(s) and source are credited. $\mathrm{mg} / \mathrm{dL}$ (female); blood pressure $>130 / 85 \mathrm{mmHg}$ or antihypertensive drug use; fasting plasma glucose $>100 \mathrm{mg} / \mathrm{dL}$ or hypoglycemic drug use. ${ }^{1}$ Any of these conditions and MetS itself have been associated to an increased risk of age-related cognitive decline, Alzheimer's disease (AD) and vascular dementia. ${ }^{2-6}$

The aim of our research was to assess the prevalence of MetS in a sample of elderly people belonging to a rural alpine community and investigate the relationship between MetS and cognitive performance.

The research has been reviewed and received ethics approval by the Bioethics Committee of the University of Turin, Italy.

\section{Materials and Methods}

We evaluated 174 people (97 women and 77 men) aged 60 and over (mean age $73.4 \pm 7.3$ years for males and $75.1 \pm 8.7$ years for females) living in the villages of Venaus, Mompantero and Novalesa (Cenischia Valley, Piedmont, Italy). They were recruited through the local healthcare service (ASL TO3) and they all are people whose families have been living in the valley for at least three generations. Blood samples were collected from each participant in the morning to determine plasma total, HDL-C, triglycerides and fasting plasma glucose level. Blood pressure, waist circumference, height and weight were measured and a detailed pharmacological anamnesis was recorded in order to define current assumption of drugs.

Cognitive status was assessed with the mini mental state examination (MMSE) which is the screening test most widely used for cognitive impairment (CI). ${ }^{7}$ MMSE allows the quantification of cognitive abilities and their changes over time and it has a good reliability (sensitivity $=87 \%$; specificity $=82 \%$ ). The MMSE total combines scores from five cognitive domains (orientation, language and comprehension, memory, attention, calculation and praxis), where each domain contributes approximately equal weight to the overall score. The total score was corrected by age and educational level using the scoreadjustment coefficients proposed by Magni et al. in the $1996 .{ }^{8} \mathrm{~A}$ score $<24.0$ has been accepted as indicating the presence of CI. ${ }^{9}$

All data were entered into Excel $^{\circledR}$ spreadsheets (Microsoft 2007) and analyzed with SPSS Statistics 20.0.

\section{Results}

The characteristics of the participants with (MMSE<24.0) and without $\mathrm{CI}(\mathrm{MMSE} \geq 24.0)$ are resumed in Table 1 . The average HDL-C level is lower among people with CI compared to people without CI (48.7 vs $55.9 \mathrm{mg} / \mathrm{dL}, \mathrm{P}=0.034)$. HDL-C levels lower than the recommended values ( $<40 \mathrm{mg} / \mathrm{dL}$ for males and $<50 \mathrm{mg} / \mathrm{dL}$ for females) are significantly associated with $\mathrm{CI}$ [odds ratio $(\mathrm{OR})=3.22 ; \mathrm{P}=0.017)$ ]. In our sample, 
Table 1. Characteristics of 174 participants with (mini mental state examination<24.0) and without cognitive impairment (mini mental state examination $\geq 24.0$ ).

\begin{tabular}{|c|c|c|c|}
\hline & $\begin{array}{l}\text { No cognitive impairment } \\
(n=156)\end{array}$ & $\begin{array}{c}\text { Cognitive impairment } \\
(n=18)\end{array}$ & Univariate statistics \\
\hline Age (years) & $73,7 \pm 7,9$ & $80,0 \pm 7,8$ & $t=-3,190 ; D F=172 ; p=0,002$ \\
\hline Gender (Male) & $44,9 \%(n=70)$ & $38,9 \%(n=7)$ & n.s. \\
\hline BMI $(\mathrm{kg} / \mathrm{m} 2)$ & $27,2 \pm 4,7$ & $26,9 \pm 3,2$ & n.s. \\
\hline $\mathrm{AO}$ & $51,6 \%(n=80)$ & $61,1 \%(n=11)$ & n.s. \\
\hline HTN & $76,3 \%(n=134)$ & $66,7 \%(n=12)$ & n.s. \\
\hline Systolic BP (mmHg) & $137,9 \pm 13,6$ & $134,7 \pm 13,1$ & n.s. \\
\hline Diastolic BP $(\mathrm{mmHg})$ & $74,4 \pm 5,9$ & $72,8 \pm 4,6$ & n.s. \\
\hline Glucose $(\mathrm{mg} / \mathrm{dl})$ & $109,6 \pm 29,7$ & $115,1 \pm 25,3$ & n.s. \\
\hline NIDDM & $23,2 \%(n=32)$ & $27,8 \%(n=5)$ & n.s. \\
\hline TG $(\mathrm{mg} / \mathrm{dl})$ & $131,3 \pm 45,7$ & $165,1 \pm 74,5$ & n.s. \\
\hline HTG & $40,8 \%(n=58)$ & $58,8 \%(n=10)$ & n.s. \\
\hline $\mathrm{TC}(\mathrm{mg} / \mathrm{dl})$ & $214,3 \pm 47,6$ & $181,6 \pm 47,3$ & $t=2,770 ; D F=172 ; p=0,006$ \\
\hline HTC & $44,2 \%(n=69)$ & $27,8 \%(n=5)$ & n.s. \\
\hline $\mathrm{HDL}-\mathrm{C}(\mathrm{mg} / \mathrm{dl})$ & $55,9 \pm 13,7$ & $48,7 \pm 10,2$ & $t=2,135 ; D F=172 ; p=0,034$ \\
\hline Low HDL-C & $23,7 \%(n=37)$ & $50,0 \%(n=9)$ & O.R. $=3,22($ IC95\%: $1,19-8,70 ; p=0,017)$ \\
\hline $\mathrm{TC} / \mathrm{HDL}-\mathrm{C}$ & $4,0 \pm 1,1$ & $3,8 \pm 1,0$ & n.s. \\
\hline MetS & $49,4 \%(n=77)$ & $61,1 \%(n=11)$ & n.s. \\
\hline NCEP ATPIII criteria & $2,1 \pm 1,3$ & $2,9 \pm 1,6$ & $t=-2,471 ; D F=157 ; p=0,015$ \\
\hline
\end{tabular}

DF, degree of freedom; n.s., not significant; BMI, body mass index; AO, abdominal obesity (defined by a waist circumference $\geq 102 \mathrm{~cm}$ for males and $\geq 88 \mathrm{~cm}$ for females); HTN, hypertension (BP $>135 / 85 \mathrm{mmHg}$ and/or antihypertensive drugs); BP, blood pressure; NIDDM, non insulin-dependent diabetes mellitus; TG, triglycerides; HTG, hypertriglyceridemia (TG>150 mg/dL and/or lipid-lowering drugs); TC, total cholesterol; HTC, hypercholesterolemia (TC $\geq 240 \mathrm{mg} / \mathrm{dL}$ and/or lipid-lowering drugs); HDL-C, high density lipoprotein cholesterol (Low HDL-C when $<40 \mathrm{mg} / \mathrm{dL}$ for males and <50 mg/dL for females); MetS, metabolic syndrome; NCEP ATPIII, National Cholesterol Education Program - Adult Treatment Panel III.

Values are mean \pm standard deviation or percentages ( $\mathrm{n}=$ number of cases).

however, the average total cholesterol (TC) level is lower in the group with $\mathrm{CI}$ and this could account for the association between low HDL-C and $\mathrm{CI}$. In fact, if we compare the TC/HDL-C ratio between the two groups we cannot find any difference.

The group with CI shows an increased number of MetS components (NCEP ATPIII criteria) compared to the group without CI (2.9 vs 2.1; $\mathrm{P}=0.015)$.

All the variables with statistical significance $(\mathrm{P}<0.05)$ in the univariate analysis were introduced into multivariate logistic regression analysis that showed $\mathrm{CI}$ is associated with age $(\mathrm{OR}=1.087 ; \mathrm{P}=0.009)$ and an increased number of MetS components $(\mathrm{OR}=1.54 ; \mathrm{P}=0.042)$ (Table 2).

\section{Discussion}

MetS is characterized by a clustering of risk factors for cardiovascular disease and its prevalence, similar to that for cognitive disorders, increases dramatically with age. A growing body of epidemiological evidence suggested that MetS components may be important in the development of age-related cognitive decline, vascular dementia, and
Table 2. Multivariate association of age and numbers of National Cholesterol Education Program - Adult Treatment Panel III criteria with cognitive impairment.

\begin{tabular}{|lcc|}
\hline & OR $(95 \% \mathrm{CI})$ & $\mathrm{P}$ - value \\
\hline Age (years) & $1,087(1,021-1,157)$ & 0,009 \\
NCEP ATPIII criteria & $1,540(1,039-2,284)$ & 0,042 \\
\hline
\end{tabular}

OR, odds ratio; CI, confidence interval; NCEP ATPIII, National Cholesterol Education Program - Adult Treatment Panel III.

AD. ${ }^{10,11}$ Several possible mechanisms may explain an association between MetS and CI including microvascular and macrovascular disease, inflammation, adiposity, and insulin resistance. ${ }^{12}$ Our study has some limitations, the most important the small sample size, but our results are consistent with a recent study that found an association between MetS, the number of its components and risk of developing $\mathrm{CI}$ in older women from clinical centers. ${ }^{13}$ In fact, although the prevalence of MetS in our sample is not significantly different between people with 
and without $\mathrm{CI}$, both univariate and multivariate statistics show an association between an increased number of MetS components and CI.

\section{References}

1. Grundy SM, Brewer HB Jr, Cleeman JI, et al. Definition of metabolic syndrome: report of the National Heart, Lung, and Blood Institute/American Heart Association conference on scientific issues related to definition. Circulation 2004;109:433-8.

2. Duron E, Hanon 0. Vascular risk factors, cognitive decline, and dementia. Vasc Health Risk Manag 2008;4:363-81.

3. Yaffe K, Kanaya A, Lindquist K, et al. The metabolic syndrome, inflammation, and risk of cognitive decline. JAMA- J Am Med Assoc 2004;292:2237-42.

4. Vanhanen M, Koivisto K, Moilanen L, et al. Association of metabolic syndrome with Alzheimer disease: a population-based study. Neurology 2006;67:843-7.

5. Razay G, Vreugdenhil A, Wilcock G. The metabolic syndrome and Alzheimer disease. Arch Neurol-Chicago 2007;64:93-6.
6. Raffaitin C, Gin H, Empana JP, et al. Metabolic syndrome and risk for incident Alzheimer's disease or vascular dementia: the ThreeCity Study. Diabetes Care 2009;32:169-74.

7. Folstein MF, Folstein SE, McHugh PR. 'Mini-Mental State'. A practical method for grading the cognitive state of patients for the clinician. J Psychiat Res 1975;12:189-98.

8. Magni E, Binetti G, Bianchetti A, et al. Mini-mental state examination: a normative study in Italian elderly population. Eur J Neurol 1996;3:1-5.

9. Tombaugh TN, McIntyre NJ. The mini-mental state examination: a comprehensive review. J Am Geriatr Soc 1992;40:922-35.

10. Dik MG, Jonker C, Comijs HC, et al. Contribution of metabolic syndrome components to cognition in older individuals. Diabetes Care 2007;30:2655-60.

11. Yaffe K. Metabolic syndrome and cognitive disorders: is the sum greater than its parts? Alz Dis Assoc Dis 2007;21:167-71.

12. Frisardi V, Solfrizzi V, Seripa D, et al. Metabolic-cognitive syndrome: a cross-talk between metabolic syndrome and Alzheimer's disease. Ageing Res Rev 2010;9:399-417.

13. Yaffe K, Weston AL, Blackwell T, Krueger KA. The metabolic syndrome and development of cognitive impairment among older women. Arch Neurol-Chicago 2009;66:324-8. 